\title{
TEKNIK ADAPTIF KELOMPOK MUSIK OPSI TOP FOURTY TERHADAP RUANG PERTUNJUKAN DI SURAKARTA
}

\author{
Fariz Hananto \\ Penyuka Musik Top Fourty asal Ngawi Jawa Timur \\ dapat dihubungi melalui 085600400259
}

\begin{abstract}
This article aims to reveal and explain adaptive techniques from the Top Fourty OPSI music group in the performance space in the city of Surakarta. This study used two theories, namely the theory of adaptation proposed by Suparlan and Gerungan, as well as the theory and concept of the performance space proposed by Alexander et al. in 1977. Then, the authors also conduct research by participant observation and qualitatively to obtain data in accordance with the facts in the field. From the results of this study, three adaptive techniques were found that need to be done by top fourty musicians, namely (1) the selection of songs, (2) arrangement, and (3) stage expression. The adaptive technique must be truly owned by every top fourty musician, so that they can master any kind of show space to entertain the audience.
\end{abstract}

Kata Kunci : musisi top fourty, teknik adaptif, ruang pertunjukan

\section{Landasan Konseptual}

Penelitian ini mengunakan teori dasar dari Gerungan dalam bukunya Psikologi Sosial, yang menjelaskan mengenai teori adaptasi yang dilakukan seseorang untuk memenuhi syarat-syarat melangsungkan hidup. Dalam teorinya, dia menyatakan bahwa:

"Adaptasi adalah suatu penyesuaian pribadi terhadap lingkungan . Penyesuaian berarti mengubah diri sesuai dengan keadaan lingkungan, juga dapat berarti mengubah lingkungan dengan keadaan keinginan pribadi." (Gerungan, 1991:55)
Teori ini digunakan untuk membedah bagaimana seorang pemusik top fourty beradaptasi terhadap ruang-ruang pertunjukannya. Temuan-temuan mengenai teknik adaptif yang dilakukan seorang pemusik seperti bagaimana pemilihan lagu, aransemen bahkan, ekspresi panggung di setiap ruang pertunjukan akan berbeda. Teknik-teknik tersebut digunakan seorang pemusik untuk menarik perhatian dan membawa suasana suatu pertunjukan yang tengah berlangsung.

Kelompok OPSI sebagai kelompok musik top fourty menjadi acuan untuk penelitian, mengingat jam terbang dan 
pengalaman mereka yang cukup tinggi menunjukkan berbagai teknik adaptif mereka dalam ruang pertunjukan, baik berdasarkan pengalaman sendiri maupun orang lain yang lebih dulu mengetahui seluk beluk musik top fourty. Sebagai ujung tombak suatu pertunjukan musik, teknik adaptif sangat diperlukan seorang musisi dalam menguasai ruang pertunjukan agar audiens merasa terhibur akan adanya sajian musik. Sedikit saja mereka melakukan kesalahan dan mengecewakan penonton, dampaknya akan besar dan sangat berkelanjutan, seperti kehilangan kesempatan untuk mendapat pekerjaan itu lagi, hingga hujatan dari penonton yang dapat menurunkan eksistensi mereka sebagai musisi. Hal ini akan sangat berefek kepada pemusik, entah dalam musikalitasnya, perasaan kegelisahannya, ataupun suasana di atas panggung pertunjukan itu sendiri.

Ruang yang seperti dijelaskan oleh Alexander et al. (1977) terbagi menjadi dua jenis yaitu, ruang positif merupakan ruang yang memiliki batas yang pasti dan jelas, ruang ini dapat dirasakan dan dapat diukur dengan seksama seperti tempat, atau lokasi yang memiliki volume di dalamnya. Yang kedua adalah ruang negatif yang tidak mempunyai bentuk yang jelas, jenis ruang ini sulit dijelaskan keberadaannya, namun dapat dikategorikan menurut pandangan masing-masing pribadi. Contohnya, ruang pikiran, ruang kreativitas, atau ruang-ruang tertentu yang mempunyai batas tetapi tidak dapat dilihat secara nyata. Ruang pertunjukan juga menggunakan kedua prinsip ruang tersebut. Dengan menggunakan ruang positif maka akan ada perbedaan dimana tempat satu pertunjukan berlangsung. Seperti kafe, restauran atau bahkan gedung pernikahan maupun tempat tempat lain yang dengan mudah dibedakan secara visual. Sedangkan prinsip ruang yang kedua juga digunakan dalam penelitian mengenai ruang negatif yang berupa acara pertunjukan, tema atau kondisi satu pertunjukan.

Bentuk adaptasi yang digunakan oleh kelompok musik OPSI Top Fourty ini beragam, semisal adaptasi yang digunakan untuk menghadapi audiens dalam ruang pertunjukan. Lebih jelasnya adalah aransemen yang menarik akan lebih mendapat perhatian dari penonton. Bentukbentuk aransemen yang sering digunakan oleh OPSI Top Fourty adalah aransemen sederhana seperti lagu-lagu pop yang bernuansa cinta diubah ke dalam irama bossanova yang dianggap lebih menarik perhatian audiens. Contohnya adalah lagu dangdut Pacar Lima Langkah yang dikemas jazzy sehingga membuat satu ruangan kafe ikut bernyayi bersama mereka. Sudut pandang yang dibuat sedemikian rupa 
sehingga lagu dangdutpun bisa diubah dimasukan ke dalam sajian musik Top Fourty. Hal itu juga dikuatkan dalam buku Soerjono Sukanto yang berjudul Sosiologi Suatu Pengantar pada tahun 2000 yang menjelaskan bahwa adaptasi dapat diartikan menjadi dua bagian yaitu proses perubahan untuk penyesuaian dengan situasi yang berubah atau merubah agar sesuai kondisi yang diciptakan. Hampir sama dengan teori dari Gerungan yang juga lebih menekankan bahwa pemusik harus beradaptasi dengan ruang pertunjukan, dengan tujuan untuk membuat suatu pertunjukan lebih menarik dan mendapatkan perhatian dari audiens yang hadir.

Yang dilakukan kelompok musik OPSI Top Fourty adalah dengan mengubah sebuah lagu berjudul Pacar Lima Langkah dari berirama dangdut menjadi berirama bossanova. Perbedaan terlihat ketika lagu tersebut diubah dengan aransemenaransemen yang kreatif untuk menimbulkan interprestasi di dalam ruang pertunjukan. Karena jika lagu Pacar Lima Langkah tidak diubah, lagu yang berirama dangdut tersebut tidak akan tepat jika dimainkan pada suasana kafe yang tengah tenang dan santai. Di situlah letak adaptasi yang terlihat, dimana pemilihan lagu, aransemen dan ekspresi panggung benar-benar disesuaikan dengan ruang yang ada.

\section{Riwayat Kelompok Musik OPSI Top Fourty}

Kelompok Musik OPSI Top Fourty mulai terbentuk pada awal bulan Februari tahun 2008 dengan nama OPSI. Nama OPSI itu sendiri sebenarnya hanya seadanya, tanpa ada arti apa-apa. Nama OPSI dipilih karena sang gitaris, Adji, tertarik dengan grup musik kakaknya yang telah lebih dulu memiliki kelompok musik jazz bernama OPSA. Pemilihan instrumen pada awalnya hanya menggunakan alat musik band pada umumya, dengan drum, gitar 1, gitar 2, keyboard, vokal, dan bass. Gaya musik yang digarap oleh mereka sedikit demi sedikit mulai merambah genre jazz. Beberapa lagu jazz standard yang pernah mereka bawakan adalah Take Five yang dipopulerkan oleh Dave Brubeck pada tahun 1959, Fly Me to The Moon yang dipopulerkan oleh Bart Howart pada tahun 1954, dan yang tak kalah sering mereka mainkan adalah lagu Spain milik Chick Corea yang dipopulerkan pada tahun 1971. Walaupun kebanyakan lagu mereka merupakan lagu yang standar, namun mereka tetap mengakui bahwa lagulagu tersebut begitu sulit dikuasai. Dengan semangat dan kerja keras, mereka pernah meraih juara pada festival band di kota Solo pada tanggal 8 Desember 2008, dalam satu acara festival band pelajar di Sriwedari. Dengan mengandalkan aransemen jazz dan membawakan lagu Fly Me to The Moon, 
mereka meraih juara pertama dalam pagelaran tersebut. Suatu prestasi awal yang membanggakan bagi OPSI Top Fourty.

Adji mencoba mengenalkan beberapa musisi yang sering membawakan lagu-lagu jazz yang cukup tenar di dunia industri musik internasional. Lagu dari Jimmy Smith, John Coltrane, Mile Davis dan Rover Washington dan beberapa musisi Indonesia yang juga merupakan musisi jazz yang menjadi referensi Adji, antara lain Indra Lesmana, Bubi Chen, Jack Lesmana dan Mus Mudjiono. Adji berlatih dan menirukan beberapa karya dari musisimusisi tersebut untuk dimainkan dan di aransemen ulang agar menjadi lebih menarik. Kelompok musik OPSI Top Fourty memilih genre jazz karena menurut mereka genre inilah yang paling menantang dan asyik untuk dipelajari; dengan tempo dan accord yang berbeda, mereka mampu menuangkan segala kreatifitas mereka di musikjazz. Dengan musik jazz mereka dapat berkembang semakin maju. Tidak hanya piawai dalam membawakan lagu jazz, kelompok musik OPSI Top Fourty juga tidak segan-segan mengubah musik dangdut menjadi lebih nge-jazz kata mereka. Lagu dangdut yang disulap antara lain, Pacar Lima Langkah, Sik Asik dan masih banyak lagi lagu-lagu dangdut yang benar-benar dirubah total demi memenuhi hasrat berkreativitas mereka.
Genre awal dari kelompok musik OPSI adalah standard jazz, di mana mereka selalu membawakan lagu-lagu jazz di setiap penampilannya. Pilihan lagunya pun selalu mereka pelajari dari mas Didik yang merupakan guru musik gereja. Berjalan beberapa bulan, kelompok musik OPSI sempat memenangi beberapa kompetisi band musik pelajar dengan mengangkat lagu Jazz, selain itu kelompok ini juga tak jarang selalu mengisi setiap acara Jazz di kota Solo seperti parkiran Jazz. Seiring berjalannya waktu tawaran-tawaran baru mulai datang, seperti acara pernikahan, hiburan kafe, ulang tahun banyak berdatangan meminta kelompok musik OPSI sebagai pengisi acara. Di sinilah perubahan mulai dibutuhkan oleh kelompok musik OPSI, Adji dan kawan-kawan mulai berpikir untuk mengubah idealisme mereka yang hanya menyajikan lagu-lagu jazz standar ke lagu top fourty. Dengan banyaknya lagu baru yang hadir, bukan tidak mungkin kelompok musik OPSI akan tenggelam jika tidak mengikuti perkembanganya. Pada tahun 2009 pada bulan Desember, mereka meresmikan kelompok musik OPSI menjadi OPSI Top Fourty. Penambahan istilah Top Fourty memilki tujuan agar masyarakat mengetahui bahwa kelompok musik ini selalu membawakan lagu-lagu top fourty dalam setiap pertunjukannya. 
Menurut mereka, musik Top Fourtylah yang paling banyak diminati masyarakat, selain dapat menyatu dengan berbagai acara resmi maupun tidak resmi musik ini juga dapat merangkul semua aliran musik menjadi satu sajian yang menarik. Proses demi proses mereka jalani, mulai belajar dari musisi-musisi Top Fourty di kota Solo hingga selalu memperbarui referensi lagu yang sedang populer pada masa ini. Pada awalnya proses ini dirasa berat oleh kawan-kawan OPSI karena mereka harus lebih giat latihan untuk menambah referensi lagi. Tapi pada akhirnya kelompok musik ini untuk kedua kalinya berhasil merebut hati masyarakat dan menjadi satu kelompok musik Top Fourty yang disegani di kota Solo.

\section{Teknik Adaptif terhadap Ruang Pertunjukan}

Adaptasi terhadap ruang-ruang pertunjukan sangat diperlukan dalam sebuah pementasan kususnya sajian musik top fourty, di mana dalam satu ruang yang berbeda pemusik harus benar-benar memahami karakter tempat, audiens, maupun acara yang berlangsung. Adaptasi ini difungsikan sebagai cara dari pemusik untuk dapat membawa suasana dan memeriahkan acara dalam satu pertunjukan. Tidak hanya sekedar piawai bermain musik namun pemusik wajib memiliki kemampuan untuk membuat seluruh audiens merasa terhibur dan merasa puas akan pertunjukan musik yang mereka sajikan.

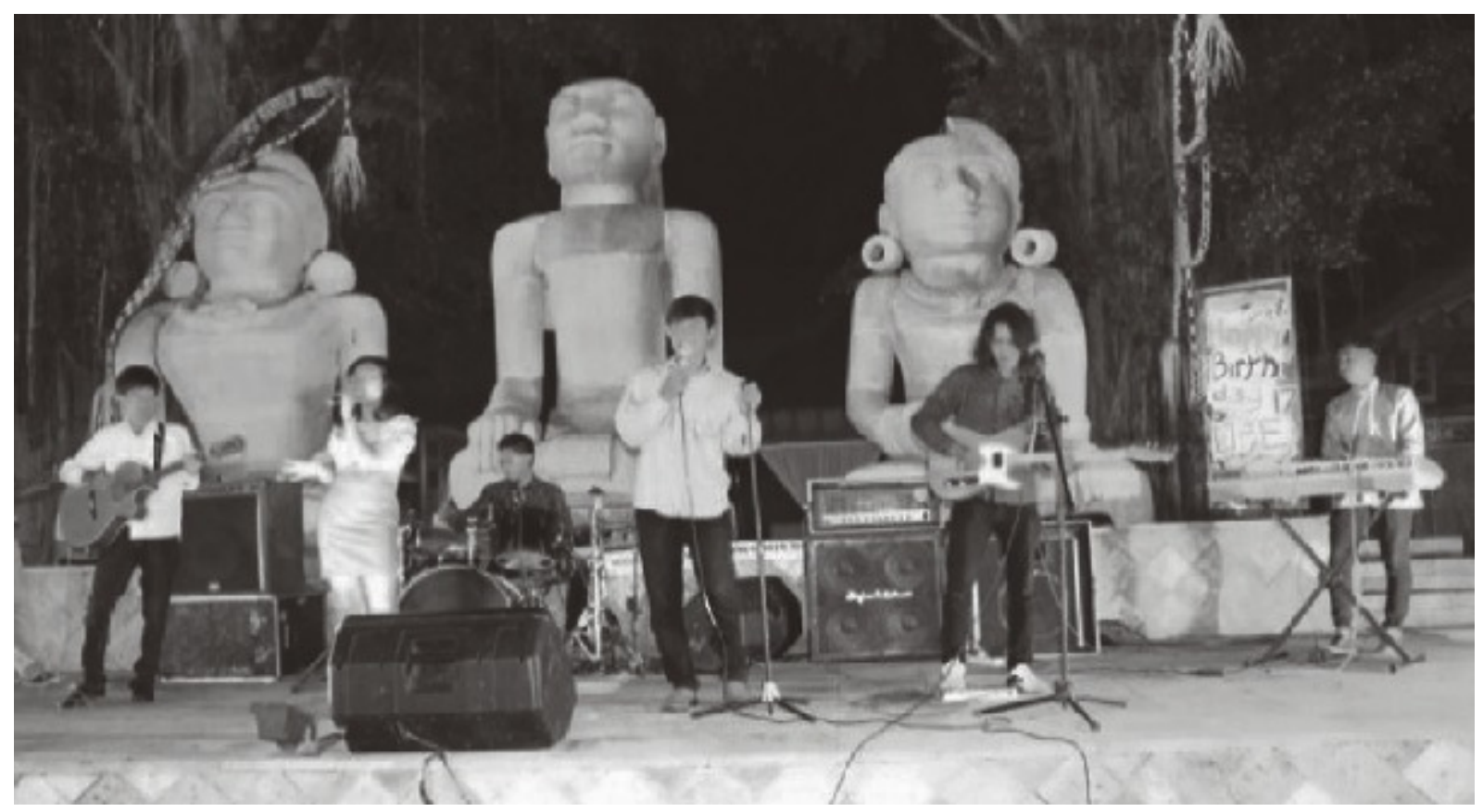

Gambar 1. Awal terbentuknya kelompok musik OPSI Top Fourty (Foto: Dokumen pribadi OPSI Top Fourty) 
Kelompok musik OPSI Top Fourty juga melakukan adaptasi ruang pertunjukan ketika mereka melakukan sebuah pementasan. Banyak hal yang mereka siapkan ketika menghadapi ruang-ruang yang berbeda. Mulai dari pemilihan lagu, aransemen musik, ekpresi panggung hingga instrumen musik yang mereka persiapkan untuk menghadapi berbagai ruang pertunjukan. Walaupun dengan persiapan yang begitu matang, tak jarang mereka selalu menemukan kendala baru yang dihadapi ketika melakukan sebuah pementasan. Bagi mereka, itu adalah sebuah tantangan yang harus diselesaikan dengan baik sehingga dapat menghibur penonton tanpa adanya kesalahan yang fatal. Adaptasi dianggap penting karena tanpa adaptasi dari seorang pemusik, pertunjukan akan berjalan biasa tanpa adanya interaksi antar penonton dan tidak akan adanya kemeriahan yang dicapai ketika pertunjukan berlangsung. Adaptasi yang dilakukan OPSI selalu memberikan warna yang berbeda ketika mereka melakukan suatu pementasan. Selalu ada hal-hal baru yang muncul dengan sendirinya ketika pertunjukan berlangsung. Hampir semua pemain memiliki kemampuan beradaptasi dengan baik terhadap ruang pertunjukan sehingga mereka selalu mendapatkan apresiasi baik dari audiens maupun acara. Melalui berbagai panggung pertunjukan mereka selalu menemukan cara-cara tersendiri dalam beradaptasi seperti pada acara wedding, acara non formal seperti di kafe maupun dalam konser besar. Terdapat caracara yang berbeda ketika mereka menghadapi ruang-ruang pertunjukan tersebut, dan tentu saja akan selalu ada kendala dan tantangan tersendiri di setiap ruang pertunjukan yang mereka hadapi.

\section{Teknik Adaptif dalam Kafe}

Kafe merupakan satu tempat untuk sekedar bersantai atau berkumpul bersama kawan kawan. Di tempat ini biasanya tersedia berbagai macam makanan atau kopi yang disediakan untuk menemani para pengunjung yang ingin duduk bersantai. Tak ayal, kini kafe merupakan tempat favorit yang sering dikunjungi masyarakat kususnya di kota Solo. Di kota besar seperti Solo banyak tersedia kafe dengan berbagai macam konsep; ada yang modern, elegan, bahkan tradisional. Semua memiliki keistimewaan dan keunggulan masingmasing dalam memanjakan pengunjung. Selain tempat yang nyaman dan sajian makanan yang lezat, musik juga menjadi pilihan tersendiri bagi pemilik kafe untuk mendapat perhatian lebih dari konsumen. Tak jarang musik live selalu menjadi daya tarik tersendiri bagi pengunjung kafe. Bahkan ada pengunjung kafe yang datang bukan untuk makan atau nongkrong namun 
ingin menikmati musik yang tengah disajikan.

Kelompok musik OPSI Top Fourty memiliki cara-cara tersendiri untuk menjadi bagian dari kafe tersebut. Adaptasi-adaptasi digunakan demi meraih keberhasilan dan kepuasaan audiens ketika OPSI Top Fourty melakukan pementasan. Cukup banyak adaptasi yang diperlukan untuk beradaptasi dengan suasana kafe, mengingat banyak pengunjung yang datang dalam berbagai usia dan kalangan yang tentunya memiliki selera musik yang berbeda-beda. Tidak hanya disitu, OPSI Top Fourty juga memiliki teknik adaptif yang digunakan untuk beradaptasi dengan ruang itu sendiri. Di kafe yang merupakan tempat santai dan informal, OPSI Top Fourty selalu menyajikan sajian yang dapat dinikmati berbagai kalangan seperti pemilihan lagu, aransemen dan ekpresi panggung bahkan instrument musik yang tentunya memiliki ciri tersendiri untuk memenuhi adaptasi terhadap ruang pertunjukan itu sendiri.

\section{Pemilihan Lagu}

Di dalam kafe, pemilihan lagu begitu luas jika dibandingkan dengan acara pernikahan yang tentunya lebih fokus terhadap di lagu-lagu cinta maupun betemakan kebahagiaan. Pemilihan lagu di dalam kafe akan lebih beragam karena mayoritas pengujungnya tidak dibatasi dengan usia maupun golongan. Kelompok musik OPSI Top Fourty mengatasinya dengan selalu menambah referensi tentang lagu-lagu mancanegara maupun lokal yang tengah populer. Tentu saja banyak kesulitan yang mereka dapatkan mengingat lagu-lagu yang bermunculan sangatlah banyak dan tidak terbatas. Mulai dari grup lokal Indonesia yang hampir setiap minggunya memproduksi lagu-lagu baru. Beberapa hal yang mereka lakukan ialah membuat daftar lagu yang tengah tenar pada setiap bulannya. Hal itu bertujuan agar mereka mengetahui dengan pasti apa saja lagu yang harus dipelajari dan dibawakan untuk audiens. Lagu-lagu yang mereka pelajari mulai dari tahun 2000-2017, hal itu dipastikan adalah salah satu cara untuk menambah wawasan tentang lagu-lagu yang tengah hits.

Beberapa trik yang digunakan oleh OPSI untuk memenuhi permintaan request dari penonton apabila mereka tidak mengetahui lagu yang dimaksud, antara lain (1) mengganti lagu, (2) menebak progresi akor, atau (3) menyimpan request untuk hari berikutnya.

\section{Mengganti Lagu}

Permintaan lagu setiap orang di kafe tentu saja akan sangat beragam, karena mereka datang dari tempat yang berbeda dan memiliki selera musik masing-masing. Semua orang memiliki memori tersendiri 
akan lagu yang mereka hafal dan mereka inginkan untuk dinyanyikan. Di sinilah peran dari pemusik untuk tetap memuaskan setiap orang yang request tanpa mengecewakanya. Teknik mengganti lagu adalah hal yang pertama dilakukan ketika terdapat audiens yang request dan memberikan uang tips namun pemusik tidak tahu sama sekali tentang lagu tersebut. Kelompok musik OPSI Top Fourty memiliki cara untuk mengatasinya, yaitu dengan terlebih dahulu membuat daftar lagu yang tengah hits dari masa ke masa dalam sebuah buku referensi. Buku tersebut difungsikan untuk memberikan tawaran kepada audiens untuk memilih lagu lain. Biasanya langkah awal yang mereka lakukan adalah dengan menawarkan lagu yang berbeda namun dari satu pencipta yang sama. Sebut saja kasus yang mereka alami adalah ketika ada satu pelanggan yang meminta lagu Chrisye yang berjudul Seindah Rembulan (tahun 1980), dan tidak ada satupun personil yang mengetahui lagu tersebut, maka yang mereka lakukan adalah menawarkan lagu Chrisye yang lain, semisal Cinta, yang tentunya banyak orang yang mengenalnya. Cara ini dianggap salah satu trik yang cukup jitu untuk tetap memuaskan pelanggan yang ingin menyanyikan lagu.

Daftar lagu yang dipersiapkan OPSI Top Fourty

\begin{tabular}{|l|l|l|l|}
\hline No. & Judul Lagu & Musisi/Kelompok Musik & Tahun \\
\hline 1 & Ada Gajah di Balik Batu & Wali & 2017 \\
\hline 2 & Anganku Anganmu & Isyana feat. Raisa & 2017 \\
\hline 3 & Bahagia Itu Sederhana & Winda feat. Abdul & 2017 \\
\hline 4 & Belahan Jantungku & Andien & 2017 \\
\hline 5 & Cukup Tahu & Rizky Febian & 2017 \\
\hline 6 & Dari Mata & JAZ & 2017 \\
\hline 7 & Dengarlah Sayang & D'Masiv & 2017 \\
\hline 8 & Dia & Anji & 2017 \\
\hline 9 & Gita Cinta & Sheryl Sheinafia & 2017 \\
\hline 10 & Indah Pada Waktunya & Gisel & 2017 \\
\hline 11 & Intuisi & Yura Yunita & 2017 \\
\hline 12 & Jalan Terus & Afgan & 2017 \\
\hline 13 & Wanitaku & NOAH & 2017 \\
\hline 14 & Jangan Ajak-Ajak Dia & Melly Goeslaw & 2017 \\
\hline 15 & Jangan Cintai Aku Apa Adanya & Tulus & 2017 \\
\hline 16 & Jangan Hilangkan Dia & Rossa & 2017 \\
\hline & & & \\
\hline
\end{tabular}




\begin{tabular}{|l|l|l|l|}
17 & Kamulah Takdirku & Raffi Ahmad feat. Nagita & 2017 \\
\hline 18 & Kasmaran & JAZ & 2017 \\
\hline 19 & Kau Adalah & Isyana Sarasvati & 2017 \\
\hline 20 & Kau Terindah & Aliando & 2017 \\
\hline 21 & Kedua Kalinya & Sheryl Sheinafia & 2017 \\
\hline 22 & Kesempurnaan Cinta & Rizky Febian & 2017 \\
\hline 23 & Kokorono Placard & JKT48 & 2017 \\
\hline 24 & Ku Dengannya Kau Dengan Dia & Afgan & 2017 \\
\hline 25 & Kunci Hati & Afgan & 2017 \\
\hline 26 & Kutunggu Kau Putus & Sheryl feat. Ariel & 2017 \\
\hline 27 & Merawat Cinta & Anji & 2017 \\
\hline 28 & Mimpi & Isyana Sarasvati & 2017 \\
\hline 29 & Percayalah & Afgan feat. Raisa & 2017 \\
\hline 30 & Rock' $n$ Love & Kotak & 2017 \\
\hline 31 & Rumahku & Gita Gutawa & 2017 \\
\hline 32 & Sajadah Panjang & NOAH & 2017 \\
\hline 33 & Salamku untuk Kekasihmu & RAN feat. Kahitna & 2017 \\
\hline 34 & Sampai Kau Jadi Milikku & Judika & 2017 \\
\hline 35 & Sebelah Mata & Armand Maulana & 2017 \\
\hline 36 & Sekali Lagi & Isyana Sarasvati & 2017 \\
\hline 37 & Suara Pikiranku & NOAH & 2017 \\
\hline 38 & Tanda Mata & Glenn Fredly & 2017 \\
\hline 39 & Teka-Teki & Kotak feat. Anggun & 2017 \\
\hline & & & \\
\hline
\end{tabular}

\section{Menebak Progresi Accord}

Menebak progresi accord $^{1}$ dari sebuah lagu bukanlah cara yang bisa dilakukan semua musisi Top Fourty. Cara ini biasanya hanya dilakukan ketika mereka benar-benar terdesak oleh request dari audiens yang telah memberikan tips dan ingin bernyanyi lagu tersebut tanpa mau diganti dengan lagu lain. Inilah yang menjadi tantangan paling berat bagi pemain musik Top Fourty, dimana mereka akan menebak progresi dari lagu tersebut tanpa pernah mendengarkan lagu tersebut. Hal ini dilakukan dengan cara meminta audiens untuk menyanyikan terlebih dahulu lagu yang dimaksudkan dan kemudian temanteman mengikuti dengan menebak chord yang pas untuk lagu tersebut. Bukan hal yang mudah untuk melakukan hal tersebut, seringkali terjadi kesalahan ketika menebak

${ }^{1}$ Progresi Chord adalah pengembangan accord; penggunaan accord-accord yang sesuai guna mencapai keindahan yang sempurna sebagai pengiring melodi pokok (Pono Banoe, 2003:83) 
chord dan alhasil lagu menjadi fals dan kurang enak didengar. Selain itu, kepekaan terhadap nada sangat diperlukan untuk menebak nada dari penyanyi, ketepatan nada harus benar-benar pas agar tidak terjadi kesalahan yang membuat rusaknya lagu.

Instrumen yang biasanya menjadi ujung tombak untuk menebak progresi chord adalah bass, karena pemain basslah yang harus lebih peka nada dan membimbing instrumen lainnya agar mengikuti langkahnya dalam menebak chord. Selain itu, terkadang Adji yang paling berperan untuk membantu teman-temanya dalam menebak chord. Ia biasanya membantu temanya dengan beberapa kode tangan seperti menunjuk angka dengan jari, yang berarti setiap angka tersebut menunjukan chord yang akan dimainkan pada birama berikutnya. Contohnya, ketika jari memposisikan angka satu, berarti chord yang harus dimainkan adalah chord pertama atau DO Major dari tangga nada tersebut. Jika jari menunjukan angka dua, berarti chord yang digunakan adalah chord kedua dari tangga nada yang disepakati, begitu seterusnya. Hal yang begitu sederhana, namun sangat berpengaruh dalam setiap pertunjukan kelompok musik OPSI Top Fourty. Ilmu ini mereka dapatkan ketika belajar bersama mas Didik di gereja saat melakukan pelayanan. Tanpa menggunakan kode tangan, kelompok musik OPSI Top Fourty akan sangat kesulitan dalam berkomunikasi di atas panggung. Kode tangan yang dimaksudkan adalah sebagai berikut:

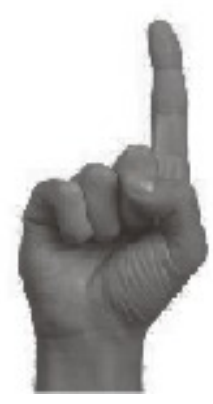

(Gambar 1)

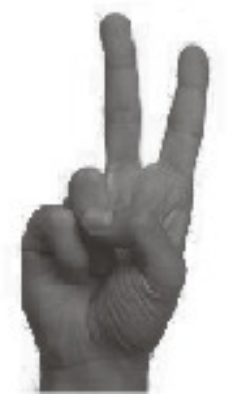

(Gambar 2)

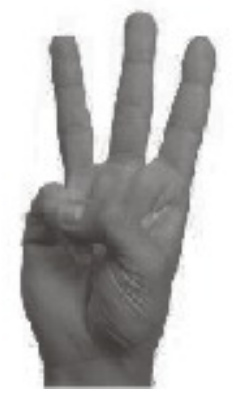

(Gambar 3)

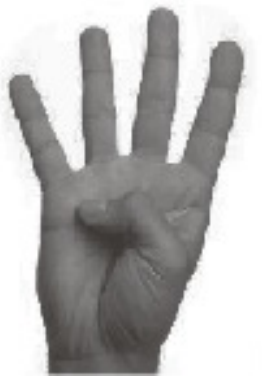

(Gambar 4)

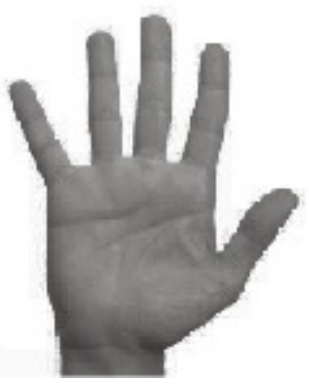

(Gambar 5)

Gambar 2. Kode-kode dalam progresi chord (Sumber: Dokumen pribadi Adji Christian) 
Keterangan:

1) Gambar untuk chord I Mayor.

2) Gambar untuk chord II Minor.

3) Gambar untuk chord III Minor.

4) Gambar untuk chord IV Mayor.

5) Gambar untuk chord V Mayor.

6) Dan seterusnya.

Selain menggunakan kode jari, Adji juga terkadang memberikan kode-kode tersebut melalui ucapan yang disampaikan langsung kepada seluruh personil. Hal ini difungsikan agar kesalahan ketika menebak progresi chord dapat di minimalkan. Selain itu setiap personil diwajibkan menguasai alatnya masing-masing agar dapat seminimal mungkin melakukan kesalahan ketika mereka melakukan progresi chord. Karena apabila mereka tidak mengusai alat musiknya secara keseluruhan, maka kemungkinan terjadi gagal dalam berkomunikasi diantara setiap personil akan lebih besar. Hal wajib yang harus benar benar diperhatikan oleh setiap personil adalah menghafal setiap chord dalam setiap tangga nada seperti yang tertera dibawah ini.

Tangga nada Natural : C-Dm-Em-F-G-Am-Bdim-C

\section{Tangga Nada \# (kres)}

Tangga nada 1\#

Tangga nada 2\#

Tangga nada 3\#

Tangga nada 4\#

Tangga nada 5\#

Tangga nada 6\#

Tangga nada 7\#
: G-Am-Bm-C-D-Em-F\#Ddim-G

:D-Em-F\#m-G-A-Bm-C\#dim-D

:A-Bm-C\#m-D-E-F\#m-G\#dim-A

:E-F\#m-G\#m-A-B-C\#m-D\#dim-E

:B-C\#m-D\#m-E-F\#-G\#m-A\#dim-B

:F\#-G\#m-A\#m-B-C\#-D\#m-E\#dim-F\#

:C\#-D\#m-E\#m-F\#-G\#-A\#m-B\#dim-C\#

\section{Tangga Nada b (moll)}

Tangga nada $1 \mathrm{~b}$

Tangga nada $2 \mathrm{~b}$

Tangga nada $3 \mathrm{~b}$

Tangga nada $4 \mathrm{~b}$

Tangga nada $5 b$

Tangga nada $6 \mathrm{~b}$

Tangga nada $7 \mathrm{~b}$
:F-Gm-Am-Bb-C-Dm-Edim-F

:Bb-Cm-Dm-Eb-F-Gm-Adim-Bb

:Eb-Fm-Gm-Ab-Bb-Cm-Ddim-Eb

:Ab-Bbm-Cm-Db-Eb-Fm-Gdim-Ab

: Db-Ebm-Fm-Gb-Ab-Bbm-Cdim-Db

: Gb-Abm-Bbm-Cb-Db-Ebm-Fdim-Gb

:Cb-Dbm-Ebm-Fb-Gb-Abm-Bbdim-Cb 
Susunan tangga nada tersebutlah yang menjadi acuan bagi setiap personil untuk menebak chord pada sebuah lagu. Untuk memperlancar setiap kode yang diberikan, setiap personil diwajibkan menghafalkan seluruh tangga nada di atas. Hal itu diwajibkan karena setiap penyanyi akan selalu memiliki nada dasar yang berbeda dan pemusiklah yang harus mengikutinya. Selain itu demi memperlancar kode-kode yang diberikan oleh Adji setiap personil harus paham betul semua susunan tangga nada, jika yang digunakan adalah angga nada $\mathrm{G}$ misalnya, mereka harus tahu dimana accord ke dua dan seterusnya. Selain dengan cara menghafal seluruh tangga nada dasar, ada cara lain bagi OPSI Top Fourty untuk menebak progresi chord yang akan bawakan, yaitu dengan menggunakan rumus pogresi yang telah tersedia. Karena kebanyakan lagu bisanya memiliki progresi chord yang sama dan berulang-ulang sehingga sangatlah mudah jika ditebak dengan rumus tersebut. Hal ini juga digunakan sebagai sarana persiapan dalam menghadapai permintaan lagu dari penonton. Beberapa progresi accord pokok dalam lagu yang telah dirumuskan, yaitu:

\section{Common Keys and Chord Progressions}

\begin{tabular}{|c|c|c|c|c|c|c|c|c|c|c|c|}
\hline I & IV & $\mathrm{V}$ & I & I & ii & $\mathrm{V}$ & I & I & vi & IV & V \\
\hline $\mathrm{G}$ & $\mathrm{C}$ & D & $\mathrm{G}$ & $\mathrm{G}$ & Am & $\mathrm{D}$ & G & $\mathrm{G}$ & $\mathrm{Em}$ & $\mathrm{C}$ & $\mathrm{G}$ \\
\hline A & D & E & A & A & $\mathrm{Bm}$ & $\mathrm{E}$ & A & A & $\mathrm{F} \# 1$ & D & $\mathrm{E}$ \\
\hline $\mathrm{C}$ & $\mathrm{F}$ & $\mathrm{G}$ & $\mathrm{C}$ & $\mathrm{C}$ & Dm & $\mathrm{G}$ & $\mathrm{C}$ & $\mathrm{C}$ & $\mathrm{An}$ & $\mathrm{F}$ & $\mathrm{G}$ \\
\hline D & $\mathrm{G}$ & A & D & D & Em & A & D & D & $\mathrm{Bm}$ & $\mathrm{G}$ & A \\
\hline$E$ & A & B & $\mathrm{E}$ & $\mathrm{E}$ & $\mathrm{F} \# \mathrm{~m}$ & B & E & $\mathrm{E}$ & C\# & A & B \\
\hline I & vi & ii & V & I & IV & vi & V & I & V & vi & IV \\
\hline $\mathrm{G}$ & Em & Am & D & $\mathrm{G}$ & $\mathrm{C}$ & Em & $\mathrm{D}$ & $\mathrm{G}$ & D & Em & $\mathrm{C}$ \\
\hline A & $\mathrm{F} \# \mathrm{~m}$ & $\mathrm{Bm}$ & $E$ & A & D & $\mathrm{F} \# \mathrm{~m}$ & $\mathrm{E}$ & A & E & $\mathrm{F} \# \mathrm{~m}$ & D \\
\hline C & Am & $\mathrm{Dm}$ & $\mathrm{G}$ & $\mathrm{C}$ & $\mathrm{F}$ & Am & $\mathrm{G}$ & C & G & Am & $\mathrm{F}$ \\
\hline D & $\mathrm{Bm}$ & Em & A & D & $\mathrm{G}$ & $\mathrm{Bm}$ & A & D & A & $\mathrm{Bm}$ & $\mathrm{G}$ \\
\hline$E$ & $\mathrm{CHm}$ & $\mathrm{F} \# \mathrm{~m}$ & B & $E$ & A & $\mathrm{CHm}$ & $B$ & $\mathrm{E}$ & B & $\mathrm{C \# n}$ & $\mathrm{A}$ \\
\hline
\end{tabular}


Progresi chord pokok di atas merupakan rumusan yang paling dasar yang digunakan sebagian besar lagu mancanegara maupun lagu Indonesia. Terkadang dengan menggunakan rumusan itu saja mereka telah dapat menemukan progresi chord itu sendiri tanpa ada kendala sedikitpun. Tetapi hal itu tidak dapat menjadi acuan lagi ketika progresi accord lagu yang dimainkan berseberangan atau jauh berbeda dari yang telah dirumuskan. Seperti pengalaman mereka ketika menebak progresi accord dari sebuah lagu berjudul butiran debu dari kelompok musik Rumor, mereka menebak Progresi accord dengan rumus:

$\begin{array}{llllll}\text { Bagian 1: } & \text { I } & \text { VII } & \text { VI } & \text { V } & \text { IV } \\ & \text { G } & \text { F\#m } & \text { Em } & \text { D } & \text { C } \\ & & & & & \\ \text { Bagian 2: } & \text { V } & \text { IV } & \text { III } & \text { II } & \text { V } \\ & \text { D } & \text { C } & \text { Bm } & \text { Am } & \text { D }\end{array}$

Dengan berbekal Progresi Chord diatas mereka dapat memainkan lagu berjudul Butiran Debu yang dipopulerkan oleh kelompok musik Rumor pada tahun 2011 dengan lancar tanpa sebelumnya mengetahui lagu tersebut. Di situlah fungsi dari progresi accord yang telah disusun yang terkadang dapat dipakai dalam beberapa lagu.

\section{Menyimpan Request untuk Hari Berikutnya}

Cara yang terakhir merupakan hal yang sangat jarang digunakan oleh kelompok musik OPSI Top Fourty yaitu dengan cara menyimpan permintaan untuk hari berikutnya. Hal ini dilakukan apabila mereka benar-benar tidak mengetahui lagu dan memungkinkan progresi accord yang sulit untuk ditebak secara langsung oleh setiap personil. Biasanya ini terjadi karena lagu yang diminta merupakan lagu yang tidak terlalu populer dan termasuk lagu lama sehingga tidak satupun personil mengetahuinya. Kasus yang sering terjadi adalah ketika mereka bermain musik di sebuah kafe yang mewah seperti AM.PM Surakarta yang terkadang pengujungnya merupakan turis asing dari berbagai Negara seperti Amerika dan Belanda yang tengah berlibur di kota Solo. Pernah terjadi kasus ketika ada seorang turis yang ingin diiringi lagu dari Aretha Franklin yang berjudul Pink Cadillac yang popular pada tahun 1980an. Hal yang pertama dilakukan kelmpok musik OPSI Top Fourty adalah menawarkan lagu lain yang yang mereka ketahui, namun audiens ini menolak dan tetap ingin menyanyikan lagu itu karena ia ingin menyanyikanya untuk pacarnya yang 
pada kala itu juga ikut menonton. Apa boleh buat akhirnya OPSI Top Fourty dengan berat hati menolak permintaan tersebut dan meminta maaf namun berjanji akan membawakan lagu tersebut di keesokan hari. Hal ini tentu saja sangat mengecewakan bagi audiens yang meminta lagu, tapi karena ada banyak hal yang perlu dipertimbangkan apabila menerima request dan malah akan menghancurkan penampilan mereka, maka OPSI Top Fourty memutuskan untuk menolaknya secara halus.

Terkadang penolakan ini akan menimbulkan rasa kecewa tersendiri untuk personil maupun audiens yang telah meminta lagu. Kepercayaan mereka terhadap band ini akan berkurang bahkan bisa jadi nama band yang telah terbangun baik akan tercoret karena tidak dapatnya memainkan sebuah lagu yang diinginkan penonton. Terkadang respon negatif dari penonton juga akan muncul seperti sorakan atau tidak akan ada yang request pada penampilan berikutnya karena merasa band ini tidak dapat dipercaya lagi.

Bagi setiap personil, hal ini akan menjadi beban tersendiri ketika berada diatas panggung dan terdapat salah satu penonton yang kecewa. Namun hal itu malah akan membuat Adji dan temantemanya semakin tertantang dan semakin giat mempelajari beragam lagu kususnya yang pernah di request dari penonton untuk menjadi pelajaran berikutnya agar tidak ada lagi permintaan lagu yang ditolak dan mengecewakan penonton.

Ketiga cara tersebut merupakan teknik adaptif kelompok OPSI Top Fourty untuk dapat memenuhi keinginan audiens jika terjadi request. Ketiganya memiliki fungsi masing-masing yang selalu digunakan dalam setiap pementasan. Seluruh personil OPSI Top Fourty selalu memahaminya dan terus mempelajari ketiga teknik tersebut agar mereka nantinya dapat menjadi kelompok yang lebih profesional dan berkompeten dalam menggeluti bidang musik Top Fourty.

\section{Kesimpulan}

Akhirnya studi yang menggunakan metode pendekatan kualitatif dalam teknik adaptif kelompok musik OPSI Top Fourty pada ruang-ruang pertunjukan sampai pada tahap kesimpulan. Yang pertama, teknik adaptif digunakan oleh kelompok musik OPSI Top Fourty untuk dapat beradaptasi dengan seluruh aspek ruang yang ada mulai dari tempat audiens dan acara yang berlangsung. Hal ini difungsikan agar mereka dapat memberikan kenyamanan dan hiburan pada setiap ruang-ruang pertunjukan. Tanpa adanya teknik adaptif tidak akan ada keseimbangan antara ruang 
dan pemusik itu sendiri, bahkan pertunjukan tidak dapat menyatu dengan ruang yang ada. Ada dua cara yang dapat digunakan oleh pemusik untuk beradaptasi, yaitu dengan mempengaruhi audiens dan acara untuk mengikuti pertunjukan mereka, atau mengikuti audiens dan menyesuaikan pertunjukan mereka terhadap ruang yang ada.

Kedua, penulis menemukan bahwa teknik adaptif yang digunakan ada beberapa macam, yang pertama mulai hal dasar dari persiapan lagu yang benar-benar dipikirkan untuk menghadapi ruang yang ada. Setiap lagu dipilah dan dipilih sesuai kebutuhan ruang pertunjukan. Jumlah lagu referensi yang dimiliki harus benar-benar memenuhi kriteria standar, minimal 100 lagu popular barat dan 100 lagu populer Indonesia. Dengan persiapan yang matang mengenai referensi, tentunya akan mempermudah pemusik untuk beradaptasi dengan ruang pertunjukan yang memang belum pernah digunakan berpentas sebelumnya.

Teknik kedua merupakan aransemen lagu yang juga harus disesuaikan dengan ruang pertunjukan. Beberapa aransemen dibuat semenarik mungkin agar mendapat perhatian penonton. Aransemen yang sederhana juga diperlukan agar pada saat tertentu penonton atau tamu pada satu ruang pertunjukan tidak merasa terganggu akan kegiatan mereka.
Teknik yang ketiga adalah ekpresi yang disesuaikan dengan acara yang tengah berlangsung. Di sini pemusik harus berhatihati dalam berekspresi, mengingat mereka harus mengikuti tema ruang pertunjukan yang telah disediakan. Ekspresi yang dimaksud ialah bagaimana pemusik menjaga sopan santun dan tingkah laku pada acara formal dan sikap bebas pada acara non formal. selalu berhati-hatian dan menonjolkan sikap elegan akan terlihat pada satu acara formal seperti pernikahan dan sikap bebas diatas panggung juga tergambarkan apabila mereka menggelar pertunjukan di kafe atau tempat umum lainya. Ada pula efek untuk pemusik yang juga menjadi pembahasan dalam rumusan masalah, dua efek yang ditemukan pada kelompok musik OPSI Top Fourty adalah efek positif yang tentunya akan semakin mengasah keterampilan mereka dalam menghadapi ruang yang berbeda-beda, keinginan akan belajar terus-menerus akan terlihat ketika ruang-ruang itu memiliki ciri yang berbeda dan benar-benar harus ditaklukan. Efek yang kedua tentu saja ada perasaan bersalah bagi setiap pemusik yang tidak dapat memenuhi permintaan dari audiens. Hal yang paling dihindari adalah efek dimana kelompok mereka akan mendapat pandangan negatif dari masyarakat dan tidak dipercaya lagi sebagai musisi profesional. 
Berdasarkan hasil penelitian penulis, teknik adaptif kelompok musik OPSI Top Fourty terhadap ruang-ruang pertunjukan diidentifikasikan menjadi tiga teknik dasar, yaitu pemilihan lagu, aransemen, dan ekpresi panggung; dan ketiganya benarbenar harus dikuasai seorang pemusik Top Fourty.

\section{Daftar Pustaka}

Alexander et al. 1977. A Pattern Language. Oxford University Press.

Banoe, Pono. 2003. Kamus Musik. Yogyakarta: Kanisius.

Gerungan. 1996. Psikologi Sosial. Bandung: Eresco.

Soekanto, Soerjono. 2000. Sosiologi: Suatu Pengantar. Jakarta: Raja Grafindo Persada.

\section{Webtografi}

https://hobimusik.wordpress.com/mp3instrumental/istilah-dalam-musik/ diunduh pada 24 Juni 2017 pukul 12:00

https://www.hotmusiccharts.com/id/itunes/ 40 diunduh pada 24 Juni 2017 pukul 13:00

http://www.billboard.com/articles/list/6792 625/top-50-love-songs-of-alltimel diunduh pada 13 Juli 2017 pukul 09:00

https://www.thoughtco.com/top-best-love- songs-of-all-time-3248359/ diunduh pada 13 Juli 2017 pukul 10:00

\section{Narasumber}

1. Adji Christian (25 tahun), Musisi Top Fourty, Nusukan, Solo

2. Dimas Raditya (24 tahun), Musisi Top Fourty, Semarang

3. Meizal Purnomo (35 tahun), Pengajar Musik, Jebres, Solo

4. Satria Hatma (25 tahun), Musisi Top Fourty, Colomadu, Karanganyar

5. Thetaf Bangkit (24 tahun), Musisi Top Fourty, Jaten, Solo

6. Widantok (23 tahun), Anggota Solo Jazz Society, Laweyan, Solo 